BRAVILLAN JOURNAL

www.bjournal.com.br
ISSN 0100-879X

Volume 43 (5) 381-496 May 2011

BIOMEDICAL SCIENCES

AND

CLINICAL INVESTIGATION

Braz J Med Biol Res, May 2011, Volume 44(5) 445-452

doi: 10.1590/S0100-879X2011007500044

Gadolinium increases the vascular reactivity of rat aortic rings

J.K. Angeli, D.B. Ramos, E.A. Casali, D.O.G. Souza, J.J.F. Sarkis, I. Stefanon, D.V. Vassallo and C.R. Fürstenau

The Brazilian Journal of Medical and Biological Research is partially financed by

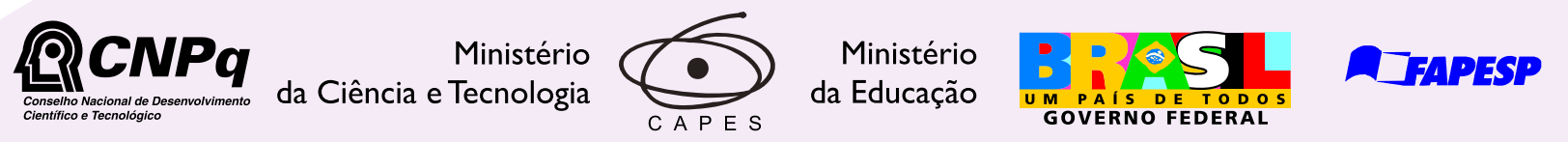

Institutional Sponsors
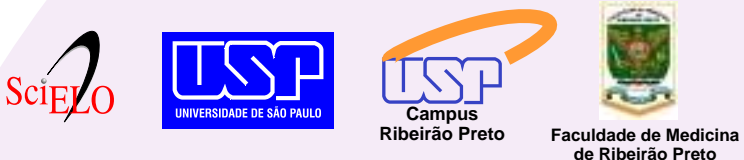

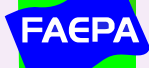

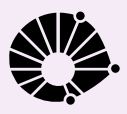

$\oplus$ SHIMADZU

GE Healthcare
Hotsite of proteomics metabolomics developped by:

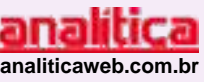

Thermo SCIENTIFIC 


\title{
Gadolinium increases the vascular reactivity of rat aortic rings
}

\author{
J.K. Angeli ${ }^{1}$, D.B. Ramos ${ }^{3}$, E.A. Casali3,4, D.O.G. Souza ${ }^{3}$, J.J.F. Sarkis ${ }^{3 \dagger}$, \\ I. Stefanon ${ }^{1}$, D.V. Vassallo ${ }^{1,2}$ and C.R. Fürstenau ${ }^{3}$ \\ 1Departamento de Ciências Fisiológicas, Universidade Federal do Espírito Santo, Vitória, ES, Brasil \\ 2Escola de Ensino Superior da Santa Casa de Misericórdia de Vitória, EMESCAM, Vitória, ES, Brasil \\ ${ }^{3}$ Departamento de Bioquímica, Instituto de Ciências Básicas da Saúde, \\ Universidade Federal do Rio Grande do Sul, Porto Alegre, RS, Brasil \\ ${ }^{4}$ Laboratório de Fisiologia e Nutrição Experimental, Centro Universitário Metodista do IPA, Porto Alegre, RS, Brasil
}

\begin{abstract}
Gadolinium (Gd) blocks intra- and extracellular ATP hydrolysis. We determined whether Gd affects vascular reactivity to contractile responses to phenylephrine (PHE) by blocking aortic ectonucleoside triphosphate diphosphohydrolase (E-NTPDase). Wistar rats of both sexes (260-300 g, 23 females, 7 males) were used. Experiments were performed before and after incubation of aortic rings with $3 \mu \mathrm{M} \mathrm{Gd}$. Concentration-response curves to PHE (0.1 nM to $0.1 \mathrm{mM})$ were obtained in the presence and absence of endothelium, after incubation with $100 \mu \mathrm{M}$ L-NAME, $10 \mu \mathrm{M}$ losartan, or $10 \mu \mathrm{M}$ enalaprilat. Gd significantly increased the maximum response (control: $72.3 \pm 3.5$; Gd: $101.3 \pm 6.4 \%$ ) and sensitivity (control: $6.6 \pm 0.1$; Gd: $10.5 \pm 2.8 \%$ ) to PHE. To investigate the blockade of E-NTPDase activity by Gd, we added $1 \mathrm{mM} \mathrm{ATP}$ to the bath. ATP reduced smooth muscle tension and $\mathrm{Gd}$ increased its relaxing effect (control: $-33.5 \pm 4.1$; Gd: $-47.4 \pm 4.1 \%$ ). Endothelial damage abolished the effect of $\mathrm{Gd}$ on the contractile responses to PHE (control: $132.6 \pm 8.6$; Gd: $122.4 \pm 7.1 \%$ ). L-NAME $+\mathrm{Gd}$ in the presence of endothelium reduced PHE contractile responses (control/L-NAME: $151.1 \pm 28.8$; L-NAME + Gd: $67.9 \pm 19 \%$ AUC). ATP hydrolysis was reduced after $\mathrm{Gd}$ administration, which led to ATP accumulation in the nutrient solution and reduced ADP concentration, while adenosine levels remained the same. Incubation with Gd plus losartan and enalaprilat eliminated the pressor effects of Gd. Gd increased vascular reactivity to PHE regardless of the reduction of E-NTPDase activity and adenosine production. Moreover, the increased reactivity to PHE promoted by Gd was endothelium-dependent, reducing NO bioavailability and involving an increased stimulation of angiotensin-converting enzyme and angiotensin II AT 1 receptors.
\end{abstract}

Key words: Gadolinium; E-NTPDase; Adenosine; Angiotensin II; AT 1 receptor

\section{Introduction}

Gadolinium (Gd) is a trivalent lanthanide cation able at $10 \mu \mathrm{M}$ to block stretch-activated calcium channels (1) and to attenuate post-ischemic myocardial stunning (2). It is currently used as a magnetic resonance contrast medium, gadobenate dimeglumine (Gd-BOPTA) (3), but concern for contrast-induced nephropathy has been reported (4). Additionally, Gd interacts with pathways involved in intra- and extracellular adenosine-5'-triphosphate (ATP) hydrolysis (5). Escalada et al. (6) showed that $3 \mu \mathrm{M} \mathrm{Gd}$ has a potent inhibitory action on ectonucleoside triphosphate diphosphohydrolase (E-NTPDase) activity in the electric organ of Torpedo marmorata. When used as a chelator, Gd can also affect the activity of angiotensin-converting enzyme (ACE) via a transmetallation effect with zinc (7).

Extracellular nucleotides, ATP, adenosine diphosphate (ADP), uridine triphosphate (UTP), and uridine diphosphate (UDP) are involved in the regulation of different biological processes in distinct tissues. Thus, extracellular ATP exhibits opposite effects depending on the concentration and on the cells and the receptors on which it acts. In the vasculature, ATP is released as a neurotransmitter from sympathetic nerves and binds to $\mathrm{P} 2 \mathrm{X}$ receptors of smooth muscle cells, producing vasoconstriction. When released from endothelial cells, it binds to P2Y receptors and initiates vasodilation (8).

Correspondence: J.K. Angeli, Programa de Pós-Graduação em Ciências Fisiológicas, Centro de Ciências da Saúde, Universidade Federal do Espírito Santo, Av. Marechal Campos, 1468, 29040-090 Vitória, ES, Brasil. Fax: +55-27-3335-7350.

E-mail: jhulikeliangeli@gmail.com

†In memoriam.

Received August 23, 2010. Accepted March 18, 2011. Available online April 1, 2011. Published May 16, 2011. 
The activity of extracellular nucleotides is terminated by a subset of enzymes called ectonucleotidases. Among them, the E-NTPDase family seems to be the most important. ENTPDase1 is the major ectonucleotidase expressed in the vasculature (9) and its activity limits platelet activation by hydrolyzing ADP (10). It has been recently demonstrated that the modulation of the expression level and activity of E-NTPDase1 in vascular smooth muscle cells (VSMCs) influences the constrictor effect of nucleotides (11). The same group has also shown that this enzyme controls the relaxation dependent on nucleotide receptor activation (12). E-NTPDase2 hydrolyses nucleoside triphosphates more rapidly than nucleoside diphosphates. E-NTPDase1 is predominantly expressed by endothelial and VSMCs, while E-NTPDase2 is associated with the adventitial surfaces (13). Together with the E-NTPDases, ecto-5'-nucleotidase is also responsible for the end of nucleotide signaling by converting adenosine monophosphate (AMP) to adenosine (14). However, the putative effect of $\mathrm{Gd}$ on vascular reactivity by inhibiting ectonucleotidase activity has not been studied. Thus, the present study was undertaken to investigate whether $\mathrm{Gd}$ might alter vascular reactivity to phenylephrine by blocking E-NTPDase activity as well as by affecting the renin-angiotensin system.

\section{Material and Methods}

\section{Chemicals}

L-phenylephrine hydrochloride (PHE), acetylcholine

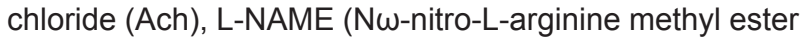
hydrochloride), enalaprilat, and gadolinium chloride were purchased from Sigma (USA). Sodium pentobarbital was obtained from Fontoveter (Brazil). These chemicals were dissolved in distilled water. All other reagents were also of analytical grade.

\section{Animals}

Wistar rats of both sexes $(260-300 \mathrm{~g}, 23$ females and 7 males) were used in the present study. The care and use of laboratory animals were in accordance with $\mathrm{NIH}$ guidelines. All rats had free access to tap water and were fed rat chow ad libitum. All experiments were conducted in compliance with the guidelines for biomedical research as stated by the Brazilian Societies of Experimental Biology and approved by the Institutional Ethics Committee, Escola Superior de Ciências da Santa Casa de Misericórdia (CEUA-EMESCAM).

\section{Tissue bath studies}

Animals were anesthetized with sodium pentobarbital ( $35 \mathrm{mg} / \mathrm{kg}$, ip) and killed by exsanguination. A section of the thoracic aorta was removed and placed in cold oxygenated Krebs-Henseleit bicarbonate buffer of the following composition: $131 \mathrm{mM} \mathrm{NaCl}, 4.7 \mathrm{mM} \mathrm{KCl}, 18 \mathrm{mM} \mathrm{NaHCO}_{3}, 2.5 \mathrm{mM}$ $\mathrm{CaCl}_{2}, 1.2 \mathrm{mM} \mathrm{KH}_{2} \mathrm{PO}_{4}, 1.2 \mathrm{mM} \mathrm{MgSO} 4,11 \mathrm{mM}$ glucose, and $0.01 \mathrm{mM}$ EDTA. The buffer was kept at $36.5^{\circ} \mathrm{C}$ and was gassed with $95 \% \mathrm{O}_{2}$ and $5 \% \mathrm{CO}_{2}$ to maintain the $\mathrm{pH}$ at 7.4. The aorta was cleaned of fat and connective tissue and cut into 4-5-mm long rings. Four to five rings were obtained from each aorta. Rings were mounted between parallel wires in tissue baths ( $5 \mathrm{~mL}$ volume). Rings were stretched to an optimal resting tension of $1 \mathrm{~g}$. Resting tension was maintained at this values and no changes were observed after incubations with $\mathrm{Gd}$ or drugs. Isometric tension was recorded using an isometric force displacement transducer (GRASS ${ }^{\circledR}$ FT03, RI, USA) connected to a data acquisition system (MP100 Biopac Systems, Inc., USA).

\section{Experimental protocols}

After 30-45 min of equilibration, each aortic ring was exposed twice to $75 \mathrm{mM} \mathrm{KCl}$ to determine its maximum contractility. Each ring was washed three times sequentially, re-equilibrated and allowed to relax to baseline. Thirty minutes later, the rings were contracted with $0.1 \mu \mathrm{M}$ $\mathrm{PHE}$, and $10 \mu \mathrm{M}$ ACh was added to assess the integrity of the endothelium. A relaxation of $90 \%$ or more indicated the functional integrity of the endothelium. Each ring was washed sequentially, re-equilibrated and allowed to relax to baseline. After $30 \mathrm{~min}$, cumulative concentration-response curves were generated for PHE ( $0.1 \mathrm{nM}$ to $300 \mu \mathrm{M})$. In other experiments, the PHE concentration-response curve was constructed in endothelium-denuded rings. The endothelium was removed by gently rubbing the intimal surface with a stainless steel rod. The effectiveness of endothelium removal was confirmed by the absence of the relaxation induced by $10 \mu \mathrm{M}$ ACh in aortas pre-contracted with PHE.

After stabilization and completion of the endothelial integrity test, a concentration-response curve to PHE (ranging from $0.1 \mathrm{nM}$ to $300 \mu \mathrm{M}$ ) was constructed in the presence and absence of $3 \mu \mathrm{M} \mathrm{Gd}$ (30-min incubation). The ability of $\mathrm{Gd}$ to reduce ATP/ADP metabolism by E-NTPDase inhibition was checked using precontractions with $0.1 \mu \mathrm{M}$ PHE followed by the addition of $1 \mathrm{mM}$ ATP. The amount of relaxation in response to ATP was measured before and after incubation with $\mathrm{Gd}$.

To determine if adenosine production and the involvement of nitric oxide (NO) are endothelium-dependent, cumulative concentration-response curves were generated for PHE (0.1 nM to $300 \mu \mathrm{M})$ under control conditions, after $100 \mu \mathrm{M}$ L-NAME, and after incubation with $100 \mu \mathrm{M} \mathrm{L-NAME}$ plus $\mathrm{Gd}$ administration. Also, to test whether $\mathrm{Gd}$ affects the generation of angiotensin II, $\mathrm{AT}_{1}$ receptors were blocked with $10 \mu \mathrm{M}$ losartan, and ACE activity was blunted with 10 $\mu \mathrm{M}$ enalaprilat.

\section{Biochemical studies}

To determine the ability of Gd in blocking E-NTPDase activity, we used a modified preparation of thoracic aorta previously reported by Levitsky et al. (15). Briefly, about 50 $\mathrm{mg}$ thoracic aorta was dissected out and the fat and connec- 
tive tissue were removed with a microscissor. The aorta was then manually processed with a motor-driven Teflon-glass homogenizer in $0.7 \mathrm{~mL}$ medium containing $100 \mathrm{mM} \mathrm{KCl}$, $30 \mathrm{mM}$ Tris- $\mathrm{HCl}, \mathrm{pH} 7.4$, and $5.0 \mathrm{mM}$ sodium azide. Each homogenate was transferred to an Eppendorf tube (1.5 $\mathrm{mL}$ ) and centrifuged at $1250 \mathrm{~g}$ for 2 min (Centrifuge 5402, Eppendorf). The supernatant (S1) was collected, and the pellet $(\mathrm{P} 1)$ was rehomogenized in $0.5 \mathrm{~mL}$ of the isolation medium. The second homogenate was centrifuged under similar conditions as described above and the extraction procedure was repeated. The pellets (P1 to P3) were discarded, and the supernatants (S1 to S3) were pooled and used for further determination of E-NTPDase activity.

E-NTPDase activity in aorta preparations was determined at $37^{\circ} \mathrm{C}$ using a reaction mixture containing $45 \mathrm{mM}$ Tris- $\mathrm{HCl}, 0.1 \mathrm{mM}$ EDTA, $2.0 \mathrm{mM} \mathrm{CaCl}_{2}, 0.5 \mathrm{mM} \mathrm{KCl}$, and 10 $\mathrm{mM}$ glucose $+210 \mathrm{mM}$ sucrose, $\mathrm{pH} 8.0$, in a final volume of $200 \mu \mathrm{L}$. About $10 \mu \mathrm{g}$ aorta protein, measured by the method of Bradford (16), was added to each tube and the enzyme reactions were initiated by the addition of substrates (ATP or ADP) at a final concentration of $2.0 \mathrm{mM}$. Gd was added to the reaction mixture from water solution at a final concentration of 75 or $100 \mu \mathrm{M}$, and E-NTPDase activity was measured in the presence or absence (control group) of Gd. These concentrations, although higher than the one used in vivo, were selected since the sensitivity of enzymes to inhibitors is reduced in in vitro experiments carried out to assess enzymatic activities (17). After 8 min of incubation, the enzyme reactions were stopped with trichloroacetic acid (TCA, $5 \%$ final concentration). Incubation time and protein concentration were chosen in order to ensure linearity of the enzymatic reactions. The amount of inorganic phosphate $(\mathrm{Pi})$ released was determined colorimetrically as described by Chan et al. (18). Controls to correct for non-enzymatic hydrolysis of substrates were obtained by adding aorta preparations after the reactions had been stopped with TCA. All experiments were performed in triplicate, and enzyme activities are reported as $\mathrm{nmol} P \mathrm{Pi}$ released per minute per milligram of protein.

The metabolism of nucleotides was also checked by high performance liquid chromatography (HPLC). We determined if the concentration of the hydrolysis products of E-NTPDase activity would change in the nutrient solution after the addition of $1 \mathrm{mM} \mathrm{ATP}$, either in the absence or in the presence of Gd. After incubation with ATP, the supernatant sample of aortic rings in different conditions (with or without $\mathrm{Gd}$ and/or PHE) was collected and centrifuged $(14,000 \mathrm{~g}$ for $10 \mathrm{~min})$. Fifty-microliter aliquots of each supernatant were applied to a reverse-phase HPLC system using a $25-\mathrm{cm} \mathrm{C}_{18}$ Shimadzu column (Shimadzu, Japan) at $260 \mathrm{~nm}$, with a mobile phase containing $60 \mathrm{mM}$ $\mathrm{KH}_{2} \mathrm{PO}_{4}, 5.0 \mathrm{mM}$ tetrabutylammonium chloride, $\mathrm{pH}$ 6.0, in $30 \%$ methanol, according to the method of Voelter et al. (19). Purine peaks (ATP, ADP, AMP, adenosine, and inosine) were identified by their retention times and quantified by comparison with standards. The results are reported as the amount of purines in $\mathrm{nmol} / \mathrm{mL}$.

\section{Statistical analysis}

Contractile responses are reported as a percentage of the maximum response to $75 \mathrm{mM} \mathrm{KCl}$. Relaxation responses to ACh are reported as the percentage of relaxation of the maximum contractile response. For each concentration-response curve, the maximum effect $\left(E_{\max }\right)$ and the concentration of agonist that produced $50 \%$ of the maximal response (log $\mathrm{EC}_{50}$ ) were calculated using non-linear regression analysis (GraphPad Prism Software, USA). The sensitivity of the agonists is reported as $\mathrm{pD}_{2}\left(-\log \mathrm{EC}_{50}\right)$. Results were analyzed by the Student $t$-test and by analysis of variance (ANOVA) followed by the Fisher post hoc test (GB-STAT, version 4.0, Dynamic Microsystem Inc., USA). Differences were considered to be statistically significant when $\mathrm{P} \leq 0.05$. To compare the effects of L-NAME on contractile responses to $\mathrm{PHE}$, the results were reported as "differences" in the area under the concentration-response curve (dAUC) to PHE in control and in experimental situations. AUC was calculated from the individual curve plots (GraphPad Prism Software), and the difference was reported as percentage of the AUC of the corresponding control situation. These values give information about whether the magnitude of the effect of L-NAME is different in control or after incubation with Gd. Data are reported as means \pm SEM with the exception of E-NTPDase activity, which is reported as means \pm SD. Differences were analyzed by the Student $t$-test or oneway ANOVA followed by the Bonferroni test. $P \leq 0.05$ was considered to be significant.

\section{Results}

Figure 1 shows that after incubation with $\mathrm{Gd}$ for 30 min, there was an increase in the contractile responses to $\mathrm{PHE}$. The concentration-response curves show that $\mathrm{E}_{\max }$ (control: $72.3 \pm 3.52$; Gd: $101.3 \pm 6.40 \%$; $P<0.05$ ) and the sensitivity (control: $6.6 \pm 0.16$; Gd: $10.5 \pm 2.81 \%$; $P<0.05$ ) to PHE increased after incubation with $\mathrm{Gd}$.

As the E-NTPDase and ecto-5'-nucleotidase cascade metabolizes ATP to adenosine, we tested the inhibitory action of Gd on these enzymes after the addition of $1 \mathrm{mMATP}$ to the tissue bath. Figure 2 illustrates the action of $\mathrm{Gd}$ on the ATP hydrolyzing activity of E-NTPDase. It can be seen that after incubation of intact rings (with endothelium) with $\mathrm{Gd}$ there was an increase in the vasorelaxation produced by ATP (control: $-33.5 \pm 4.10$; Gd: $-47.4 \pm 4.12 \%$ ), suggesting that less ATP hydrolysis occurred.

To investigate the endothelial dependence of the actions of $\mathrm{Gd}$, the same protocol was repeated with endotheliumdenuded aortic rings. Figure $1 \mathrm{~B}$ shows that, after endothelial damage, the leftward displacement of the concentrationresponse curve to $\mathrm{PHE}$ was eliminated. No changes in $\mathrm{E}_{\max }$ (control: $132.6 \pm 8.60$; Gd: $122.4 \pm 7.16 \%$ ) or $\mathrm{pD}_{2}$ (control: $8.47 \pm 0.11$; Gd: $8.17 \pm 0.26 \%$ ) were observed. Since the 
action of $\mathrm{Gd}$ is dependent on the presence of a functional endothelial layer, and the increased reactivity might result from the inhibition of vasorelaxation or from the stimulation of the release of a vasoconstrictor, we tested the putative role of $\mathrm{NO}$ using $100 \mu \mathrm{M}$ L-NAME. Figure 3 shows \%dAUC changes suggesting that $\mathrm{Gd}$ reduced the effects of L-NAME (control/LNAME: $151.1 \pm 28.8$; L-NAME + Gd: $67.9 \pm 19 \%$ AUC; $E_{\max }$ : L-NAME: $143.6 \pm 6.2$; L-NAME + Gd: $142.9 \pm 7.3 \%$, or $\mathrm{pD}_{2}$ : L-NAME + Gd: $7.13 \pm 0.1$; L-NAME: $6.99 \pm 0.23 \%$ ).

These observations could result from the blockade of adenosine production, which is a final product of the action of ectonucleotidases that exhibits vasodilator properties. Figure 4 shows that E-NTPDase activity was inhibited by 75

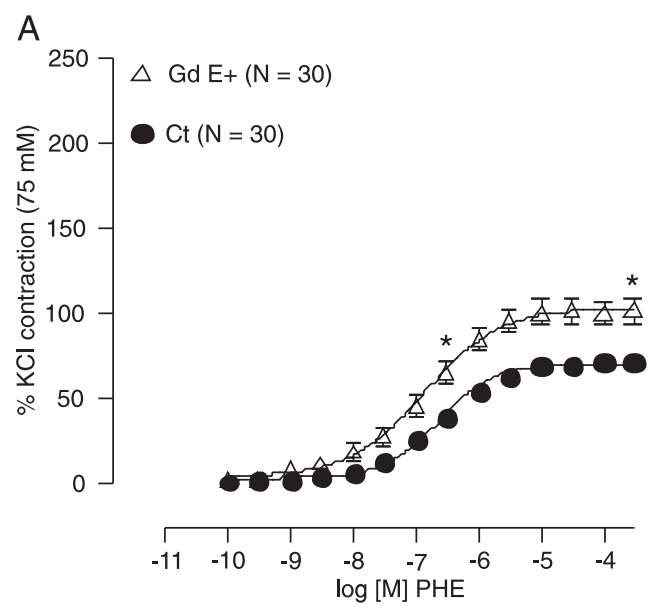

$\mu \mathrm{M} \mathrm{Gd}$ (ATP hydrolysis) and by $100 \mu \mathrm{M}$ Gd (both ATP and ADP hydrolysis) in aorta homogenates. Table 1 shows that, after ATP administration, Gd reduced ATP breakdown and ADP generation, but the final concentration of adenosine was similar to that in the control condition. To determine whether PHE could affect these results a similar protocol was used in the presence of PHE. Similar results were obtained (data not shown). According to these results, Gd might modulate extracellular ATP concentration but the increased vascular reactivity to PHE could not be explained by a reduction in adenosine production.

Since we knew that metals such as mercury at low concentration stimulate ACE activity (20) and Gd can take

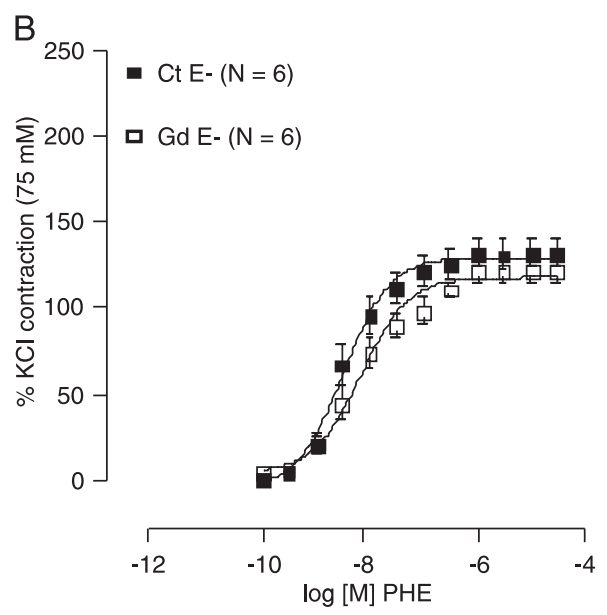

Figure 1. $A$, Concentration-response curves to phenylephrine $(\mathrm{PHE})$ in control $(\mathrm{Ct})$ rat aortic rings and in rings incubated with gadolinium (Gd) for $30 \mathrm{~min}$. An increased vascular reactivity was observed in rings with intact endothelium $\left(\mathrm{E}^{+}\right)$after $\mathrm{Gd}$ administration. An increase of the maximal response $\left(\mathrm{E}_{\max }\right)$ and sensitivity to PHE also occurred ( $\left.{ }^{*} \mathrm{P} \leq 0.05\right)$. $B$, Concentration-response curves to $\mathrm{PHE}$ in control rings ( $\mathrm{Ct} \mathrm{E}-$ ) and in rings with damaged endothelium ( $E-)$ incubated with $\mathrm{Gd}$ for $30 \mathrm{~min}$ ( $\mathrm{Gd} \mathrm{E}-$ ). Results are reported as means $\pm \mathrm{SEM}$. The maximal response $\left(E_{\max }\right)$ and sensitivity to $\mathrm{PHE}$ did not change $(P \geq 0.05$; Student $t$-test).

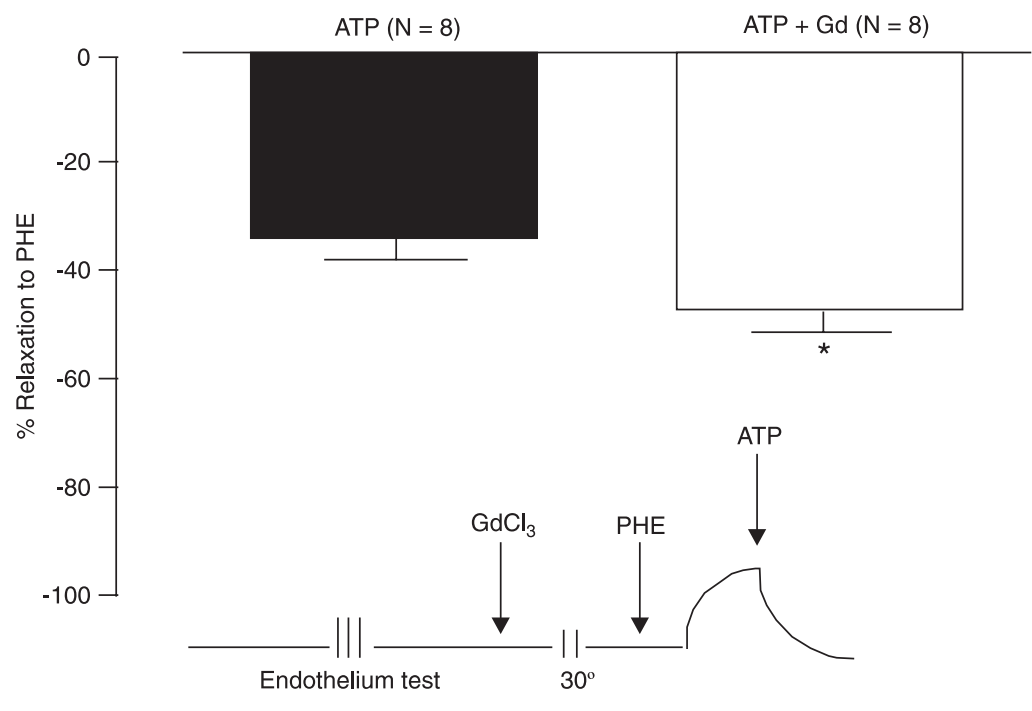

Figure 2. Relaxation (\%) in response to $1 \mathrm{mM}$ ATP after precontraction with phenylephrine (PHE) before (ATP) and after incubation with gadolinium $3 \mu \mathrm{M}$ (ATP + Gd). An important increase in relaxation was observed after incubation with $\mathrm{Gd}\left(\mathrm{N}=8\right.$; ${ }^{*} \mathrm{P} \leq 0.05$, Student $t$-test). The tracing in the lower part of the figure indicates the protocol. 
the place of zinc in the ACE molecule by transmetallation (7), we investigated whether Gd could produce a similar effect. Figure 5 shows that the action of $\mathrm{Gd}$ was blocked by both losartan, an $A T_{1}$ receptor blocker ( $E_{\text {max }}$ : losartan: 63.6
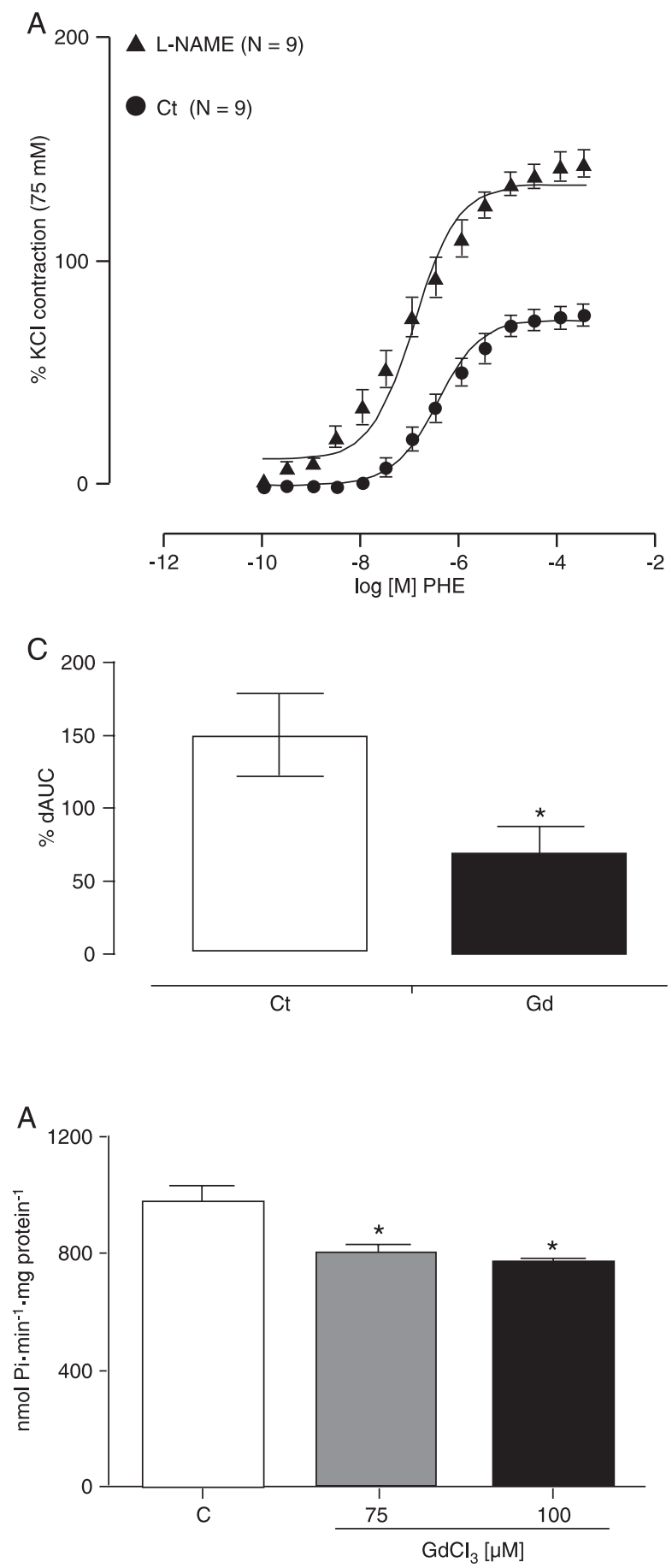

$\pm 11.3 \%$; losartan + Gd: $67.6 \pm 8.10 \%$ ), and by enalaprilat ( $E_{\text {max }}$ : enalaprilat: $69.7 \pm 6.24 \%$; enalaprilat $+\mathrm{Gd}: 70.3 \pm$ $8.15 \%)$, an ACE inhibitor. Also, the sensitivity $\left(\mathrm{pD}_{2}\right)$ to $\mathrm{PHE}$ was not altered suggesting that $\mathrm{Gd}$ stimulates ACE.

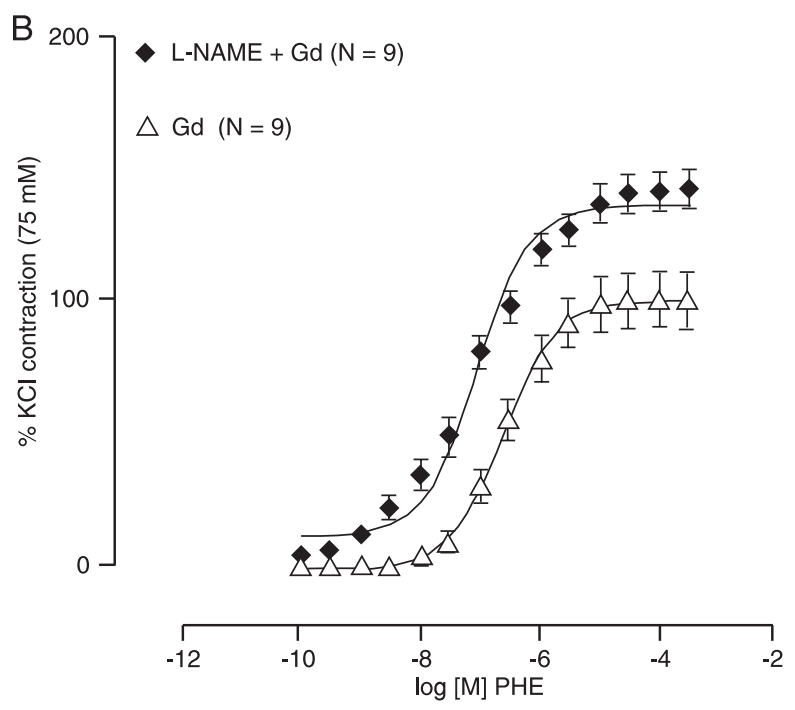

Figure 3. Concentration-response curves to phenylephrine (PHE) in control rat aortic rings (Ct), and in rings incubated for 30 min with $100 \mu \mathrm{M}$ L-NAME (L-NAME; A) and with gadolinium + L-NAME (L-NAME + Gd; B). Panel C shows the difference in area under the concentration-response curve (dAUC) before and after L-NAME in control and Gd-incubated rings. ${ }^{*} \mathrm{P} \leq 0.05$ $\mathrm{Ct} / \mathrm{L}-\mathrm{NAME}$ vs L-NAME + Gd (Student $t$-test). Data are reported as means \pm SEM.

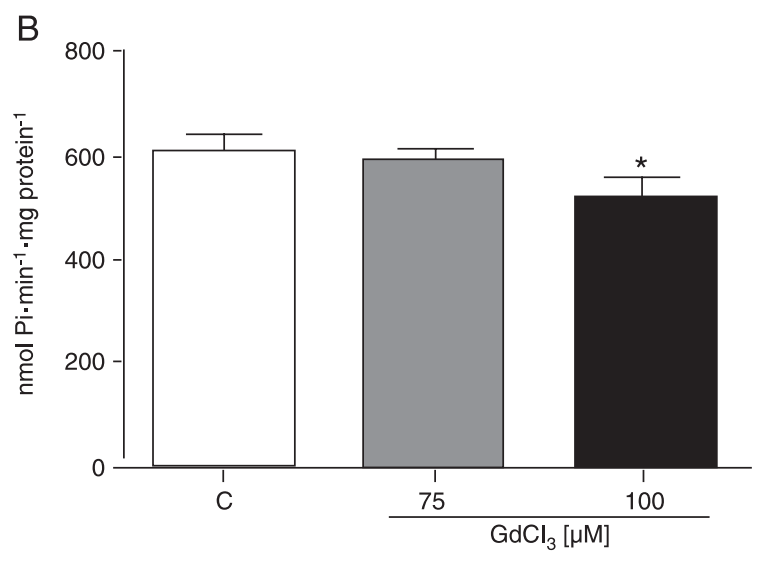

Figure 4. Effect of gadolinium chloride $\left(\mathrm{GdCl}_{3}\right)$ on ATP $(\mathrm{A})$ and $\mathrm{ADP}(\mathrm{B})$ hydrolysis by aortic rings. Data are reported as means $\pm \mathrm{SD}$ of three independent experiments. $\mathrm{C}=$ control (with no gadolinium chloride); $\mathrm{Pi}=$ inorganic phosphate. ${ }^{*} \mathrm{P} \leq 0.05$ for enzyme activity compared to control (Student $t$-test). 
Table 1. Effect of gadolinium (Gd) on purine metabolism in rat aortic rings.

\begin{tabular}{lccccc}
\hline & ATP & ADP & AMP & ADO & INO \\
\hline Control & 0 & $8.50 \pm 4.50$ & $3.25 \pm 1.00$ & $1.75 \pm 0.50$ & 0 \\
Gd & $1.75 \pm 0.25$ & $4.25 \pm 1.00$ & $2.95 \pm 0.73$ & $1.50 \pm 0.75$ & 0 \\
ATP & $291.75 \pm 53.75$ & $20.25 \pm 2.25$ & $3.00 \pm 0.50$ & $1.25 \pm 1.00$ & $1.00 \pm 0.75$ \\
ATP + Gd & $666.25 \pm 5.25^{*}$ & $4.00 \pm 7.25^{*}$ & $3.50 \pm 1.75$ & $1.00 \pm 0$ & $2.50 \pm 1.50$ \\
\hline
\end{tabular}

ATP $=$ adenosine triphosphate $; \mathrm{ADP}=$ adenosine diphosphate; $\mathrm{AMP}=$ adenosine monophosphate; $A D O=$ adenosine; INO = inosine. Data are reported as means \pm SEM (nmol/mL). ${ }^{*} \mathrm{P} \leq 0.05$ ATP vs ATP + Gd (Duncan test).

A

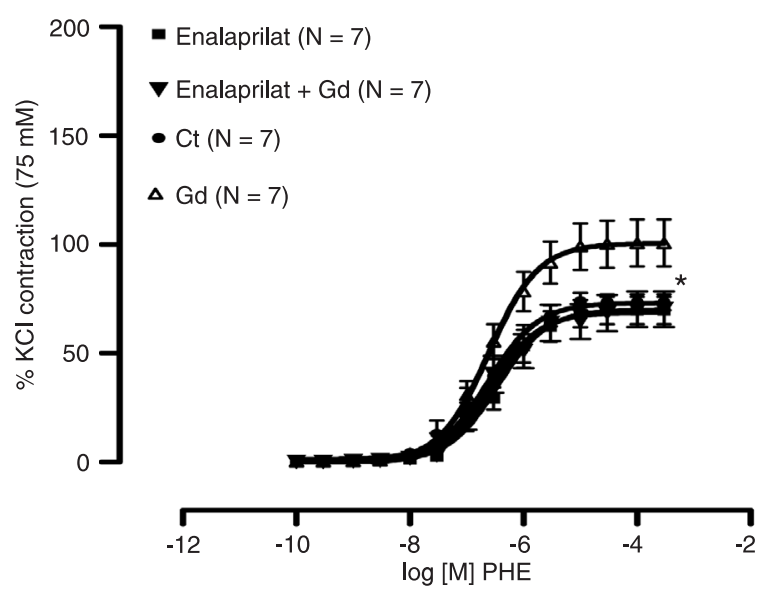

B

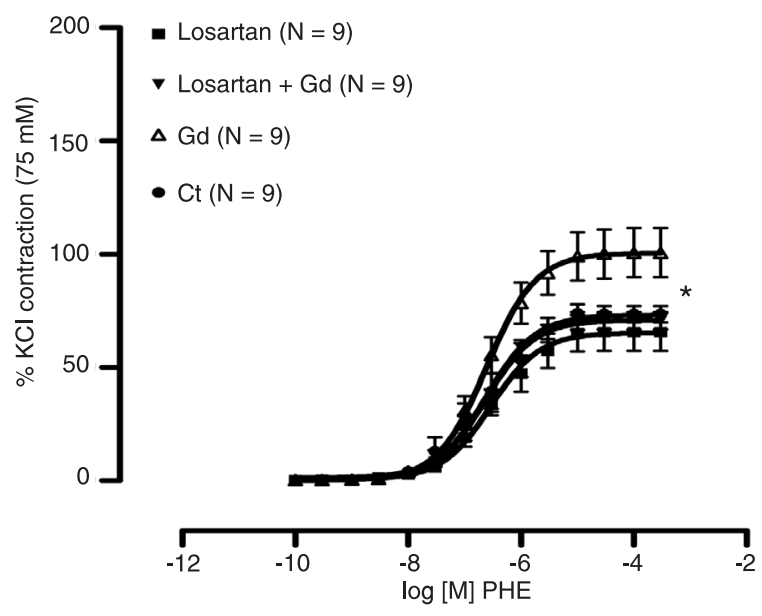

Figure 5. Concentration-response curves to phenylephrine (PHE) before and after $3 \mu \mathrm{M}$ gadolinium (Gd) in controls (Ct), after 10 $\mu \mathrm{M}$ enalaprilat (Panel A) or after $10 \mu \mathrm{M}$ losartan incubation (Panel $B$ ) in aortic rings with intact endothelium. Data are reported as means \pm SEM. ${ }^{*} E_{\max } \mathrm{P} \leq 0.05-\mathrm{Gd} v s \mathrm{Ct}$, enalaprilat and losartan, enalaprilat $+\mathrm{Gd}$ and losartan $+\mathrm{Gd}$ (Student $t$-test).

\section{Discussion}

The results presented here show that $\mathrm{Gd}$, in addition to blocking ATP and ADP hydrolysis, increased the vascular reactivity of rat aortic rings to $\mathrm{PHE}$ by a mechanism involving the stimulation of angiotensin II $\mathrm{AT}_{1}$ receptors and reduced $\mathrm{NO}$ bioavailability. Gd had no effect on the concentrationresponse curves to PHE when the endothelial layer was removed, suggesting dependence on the endothelium for the increase in vascular reactivity induced by $\mathrm{Gd}$.

Gadolinium is a potent inhibitor of E-NTPDases at the concentration of $3 \mu \mathrm{M}$ in the electric organ of Torpedo (6). However, the role of E-NTPDases in the regulation of vascular tone is not completely understood. Since the enzymes that generate adenosine are expressed in the vessel wall, we performed experiments to investigate the efficiency of $\mathrm{Gd}$ in blocking NTPDase in the rat aorta to determine whether this inhibition could affect the vascular tone. Gd proved to be a potent inhibitor of NTPDase in the rat aorta. Since adenosine is a vasodilator molecule in several vascular beds (21), the blockade of its generation by inhibiting E-NTPDase activity should increase vascular reactivity.

To confirm if $\mathrm{Gd}$ interacts with ATP breakdown, we used another protocol measuring the aortic ring relaxation by ATP before and after incubation with $\mathrm{Gd}$. Rings were precontracted with PHE and ATP was added to the bath. An enhanced relaxation effect was observed after incubation with Gd. Assuming that ATP degradation was reduced after incubation with $\mathrm{Gd}$, our results suggest that $\mathrm{Gd}$ blocked E-NTPDase activity at the endothelial level.

Indeed, our findings showed that, in the presence of endothelium, incubation with Gd caused an upward displacement of the concentration-response curves to PHE. The finding that $\mathrm{Gd}$ increased the contractile responses to PHE supports the idea that the diminished generation of adenosine could participate in a mechanism to regulate vascular tone.

In order to test whether the increased reactivity to PHE induced by incubation with $\mathrm{Gd}$ could have been produced 
by reducing the release of endothelium-derived relaxing factor, we performed a pharmacological blockade of these pathways. According to our results, incubation with L-NAME in the presence of $\mathrm{Gd}$ potentiated the vasoconstrictor response to PHE, but to a lesser extent than in the control group. These findings suggest that the effects of $\mathrm{Gd}$ were dependent on the endothelium and NO.

The next protocol was performed to assess E-NTPDase activity in aortic homogenate preparations in the presence or absence of $\mathrm{Gd}$. Several studies have reported the ability of $\mathrm{Gd}$ to decrease nucleotide hydrolysis $(6,22,23)$. In the present study, we observed that $\mathrm{Gd}$ was capable of inhibiting both ATP and ADP hydrolysis. This result supports the idea that the effect of $\mathrm{Gd}$ regarding vascular reactivity was dependent on the inhibition of ATP breakdown, which in turn could reduce adenosine production.

To clarify this issue, we performed experiments to measure ATP breakdown to ADP and adenosine. Surprisingly, as shown in Table 1, ADP formation was reduced by $\mathrm{Gd}$, but adenosine concentration was unaffected. As seen in Table 1, ATP concentration increased after Gd administration, suggesting that $\mathrm{Gd}$ was an effective inhibitor of ATP hydrolysis. The reduction of ATP breakdown explains our results showing that the vasodilator effect of ATP increased after incubation with $\mathrm{Gd}$. However, Gd also inhibits permeable ATP channels in rat hepatocytes and HTC hepatoma cells (24), suggesting that ATP transfer through the sarcolemma could be affected, possibly resulting in the maintenance of higher extracellular ATP concentration. As expected, ADP formation was reduced by $\mathrm{Gd}$. However, adenosine concentration was unaffected. This finding ruled out the possibility that $\mathrm{Gd}$ was increasing vascular reactivity by reducing adenosine generation.

Metals such as mercury, at low concentrations stimulate ACE activity (20) and Gd can take the place of zinc in the ACE molecule by transmetallation (7). We investigated whether $\mathrm{Gd}$ could produce a similar effect. ACE is a metallopeptidase that converts angiotensin I to angiotensin II, which has different biological actions and is considered to be the major effector of the renin-angiotensin system (25). Angiotensin II acts mainly through the AT 1 receptor that is expressed in many tissues, including adrenals, kidneys, heart, aorta, lungs, liver, testes, pituitary gland, and brain. When binding to the $\mathrm{AT}_{1}$ receptor, angiotensin II promotes vasoconstriction and pressor effects, also causing thrombosis, inflammation and vascular and myocardial hypertrophy (26).

We used losartan to block angiotensin II $\mathrm{AT}_{1}$ receptors and enalaprilat to block ACE, and both pre-incubations blocked the effects of $\mathrm{Gd}$ on vascular reactivity. These results suggest that $\mathrm{Gd}$ was able to increase the production of angiotensin II by stimulating ACE. A previous report showed that Gd might affect ACE activity via a transmetallation effect with zinc (7) and we recently demonstrated that another metal, mercury, at low concentration, is capable of stimulating ACE (20). Moreover, studies have shown that at lower concentrations ( $6 \mathrm{nM}$ and 0.5 to $10 \mathrm{mM}$ ), mercury induces vasoconstriction in rat caudal arteries $(20,27)$. Part of these effects are mediated by the increase in the production of reactive oxygen species and of prostanoids via cyclooxygenase $(20,27)$. This finding clarified one of the mechanisms of increased vascular reactivity produced by $\mathrm{Gd}$, which depends on an increased production of angiotensin II and an enhanced stimulation of $\mathrm{AT}_{1}$ receptors, similar to the effects reported for low concentrations of mercury $(20,27)$.

\section{Potential limitations of the study}

In the present study, we used aortic rings knowing that adenosine is more important for the regulation of tone in small arteries. However, other reports have shown that the aorta has adenosine receptors. We then decided that for a first approach the use of aortic rings would be better for us to evaluate the actions of Gd. Moreover, the main goal was to show that E-NTPDases could play a role in the control of vascular tone modulating $\mathrm{NO}$ release, and since $\mathrm{NO}$ plays an important role in the modulation of aortic tone we chose aortic rings. However, according to our findings, we believe that the results obtained in the present study are acceptable.

Our results show that Gd promoted an increase of vascular reactivity to PHE. They did not support the idea that the action of $\mathrm{Gd}$ depends on the reduction of adenosine production by the inhibition of E-NTPDase activity. However, the present results show that the in vitro exposure to $3 \mu \mathrm{M}$ $\mathrm{Gd}$ induces endothelial dysfunction in aortic segments of rats since $\mathrm{Gd}$ increased the release of vasoconstrictors from the endothelium through ACE activation and reduced bioavailability of NO. Based on these findings, we suggest that $\mathrm{Gd}$ might have toxicological consequences and might be considered to be a health risk factor.

\section{Acknowledgments} CNPq. 


\section{References}

1. Caldwell RA, Clemo HF, Baumgarten CM. Using gadolinium to identify stretch-activated channels: technical considerations. Am J Physiol 1998; 275: C619-C621.

2. Nicolosi AC, Strande JL, Hsu A, Fu X, Su J, Gross GJ, et al. Gadolinium limits myocardial infarction in the rat: doseresponse, temporal relations and mechanisms. $J \mathrm{Mol}$ Cell Cardiol 2008; 44: 345-351

3. Klein C, Gebker R, Kokocinski T, Dreysse S, Schnackenburg $B$, Fleck $E$, et al. Combined magnetic resonance coronary artery imaging, myocardial perfusion and late gadolinium enhancement in patients with suspected coronary artery disease. J Cardiovasc Magn Reson 2008; 10: 45.

4. Perazella MA. Gadolinium-contrast toxicity in patients with kidney disease: nephrotoxicity and nephrogenic systemic fibrosis. Curr Drug Saf 2008; 3: 67-75.

5. Burnstock G. Pathophysiology and therapeutic potential of purinergic signaling. Pharmacol Rev 2006; 58: 58-86.

6. Escalada A, Navarro P, Ros E, Aleu J, Solsona C, MartinSatue M. Gadolinium inhibition of ecto-nucleoside triphosphate diphosphohydrolase activity in Torpedo electric organ. Neurochem Res 2004; 29: 1711-1714.

7. Corot C, Idee JM, Hentsch AM, Santus R, Mallet C, Goulas $\mathrm{V}$, et al. Structure-activity relationship of macrocyclic and linear gadolinium chelates: investigation of transmetallation effect on the zinc-dependent metallopeptidase angiotensinconverting enzyme. J Magn Reson Imaging 1998; 8: 695702.

8. Ralevic V, Burnstock G. Involvement of purinergic signaling in cardiovascular diseases. Drug News Perspect 2003; 16: 133-140.

9. Enjyoji K, Sevigny J, Lin Y, Frenette PS, Christie PD, Esch JS, et al. Targeted disruption of cd39/ATP diphosphohydrolase results in disordered hemostasis and thromboregulation. Nat Med 1999; 5: 1010-1017.

10. Robson SC, Kaczmarek E, Siegel JB, Candinas D, Koziak K, Millan M, et al. Loss of ATP diphosphohydrolase activity with endothelial cell activation. J Exp Med 1997; 185: 153-163.

11. Kauffenstein G, Drouin A, Thorin-Trescases N, Bachelard $\mathrm{H}$, Robaye B, Orleans-Juste P, et al. NTPDase1 (CD39) controls nucleotide-dependent vasoconstriction in mouse. Cardiovasc Res 2010; 85: 204-213.

12. Kauffenstein G, Furstenau CR, Orleans-Juste P, Sevigny $J$. The ecto-nucleotidase NTPDase1 differentially regulates P2Y1 and P2Y2 receptor-dependent vasorelaxation. $\mathrm{Br} \mathrm{J}$ Pharmacol 2010; 159: 576-585.

13. Sevigny J, Sundberg C, Braun N, Guckelberger O, Csizmadia E, Qawi I, et al. Differential catalytic properties and vascular topography of murine nucleoside triphosphate diphosphohydrolase 1 (NTPDase1) and NTPDase2 have implications for thromboregulation. Blood 2002; 99: 28012809.

14. Frassetto SS, Schetinger MR, Schierholt R, Webber A, Bonan CD, Wyse AT, et al. Brain ischemia alters platelet ATP diphosphohydrolase and 5'-nucleotidase activities in naive and preconditioned rats. Braz J Med Biol Res 2000; 33: 1369-1377.

15. Levitsky DO, Clergue M, Lambert F, Souponitskaya MV, Le Jemtel TH, Lecarpentier $Y$, et al. Sarcoplasmic reticulum calcium transport and $\mathrm{Ca}^{2+}$-ATPase gene expression in thoracic and abdominal aortas of normotensive and spontaneously hypertensive rats. J Biol Chem 1993; 268: 83258331.

16. Bradford MM. A rapid and sensitive method for the quantitation of microgram quantities of protein utilizing the principle of protein-dye binding. Anal Biochem 1976; 72: 248-254.

17. Bohmer AE, Pochmann D, Sarkis JJ. In vitro effect of homocysteine on nucleotide hydrolysis by blood serum from adult rats. Chem Biol Interact 2006; 160: 159-164.

18. Chan KM, Delfert D, Junger KD. A direct colorimetric assay for $\mathrm{Ca}^{2+}$-stimulated ATPase activity. Anal Biochem 1986; 157: 375-380.

19. Voelter W, Zech K, Arnold P, Ludwig G. Determination of selected pyrimidines, purines and their metabolites in serum and urine by reversed-phase ion-pair chromatography. $J$ Chromatogr 1980; 199: 345-354.

20. Wiggers GA, Stefanon I, Padilha AS, Pecanha FM, Vassallo DV, Oliveira EM. Low nanomolar concentration of mercury chloride increases vascular reactivity to phenylephrine and local angiotensin production in rats. Comp Biochem Physiol C Toxicol Pharmacol 2008; 147: 252-260.

21. Shryock JC, Belardinelli L. Adenosine and adenosine receptors in the cardiovascular system: biochemistry, physiology, and pharmacology. Am J Cardiol 1997; 79: 2-10.

22. Buffon $A$, Ribeiro VB, Wink MR, Casali EA, Sarkis JJ. Nucleotide metabolizing ecto-enzymes in Walker 256 tumor cells: molecular identification, kinetic characterization and biochemical properties. Life Sci 2007; 80: 950-958.

23. Rucker B, Almeida ME, Libermann TA, Zerbini LF, Wink MR, Sarkis JJ. E-NTPDases and ecto-5'-nucleotidase expression profile in rat heart left ventricle and the extracellular nucleotide hydrolysis by their nerve terminal endings. Life Sci 2008; 82: 477-486.

24. Roman RM, Feranchak AP, Davison AK, Schwiebert EM, Fitz JG. Evidence for $\mathrm{Gd}^{3+}$ inhibition of membrane ATP permeability and purinergic signaling. Am J Physiol 1999; 277: G1222-G1230.

25. Kifor I, Dzau VJ. Endothelial renin-angiotensin pathway: evidence for intracellular synthesis and secretion of angiotensins. Circ Res 1987; 60: 422-428.

26. Touyz RM, Berry C. Recent advances in angiotensin II signaling. Braz J Med Biol Res 2002; 35: 1001-1015.

27. da Cunha V, Souza HP, Rossoni LV, Franca AS, Vassallo DV. Effects of mercury on the isolated perfused rat tail vascular bed are endothelium-dependent. Arch Environ Contam Toxicol 2000; 39: 124-130. 